\title{
Pelatihan Sistem Digital dan Komunikasi Menggunakan Modul Arduino pada Sekolah Menengah Kejuruan
}

\author{
Fathur Zaini Rachman $^{1 *}$, Nurwahidah Jamal ${ }^{1}$, Nur Yanti $^{1}$, Qory Hidayati ${ }^{1}$ \\ ${ }^{1}$ Jurusan Teknik Elektro Politeknik Negeri Balikpapan \\ I*fathur.zaini@poltekba.ac.id
}

\begin{abstract}
Abstrak
Kegiatan ini memiliki tujuan yaitu memberi pengetahuan dan penerapan modul praktik berbasis Arduino dalam implementasi bidang sistem digital dan komunikasi yang memiliki perangkat multi-input dan multi-output. Masalah mitra yaitu teknologi industri 4.0 dan kompetensi guru. Masalah teknologi industri 4.0 diimplementasikan dalam modul pelatihan praktik yang berguna sebagai media pembelajaran yang dapat diimplementasikan untuk berbagai aplikasi. Masalah kompetensi guru dengan pelatihan dan pengembangan media pembelajaran sehingga mampu menciptakan dan berinovasi dalam sistem digital dan komuikasi. Metode yang digunakan dalam kegiatan ini adalah diskusi akan permasalahan teknologi, sehingga didapatkan penjelasan solusi yang akan ditawarkan, dengan mendemonstrasikan alat peraga dengan uji coba latihan dan terakhir, observasi kegiatan untuk melihat hasil kegiatan. Hasil kegiatan ini meningkatkan kompetensi dan pengetahuan sekolah vokasi dengan ditandai peserta mampu mengoprasikan dan mengimplementasikan modul.
\end{abstract}

Kata Kunci: Arduino, Digital, komunikasi, industri 4.0

\section{Abstract}

This activity has the aim of providing knowledge and application of Arduino-based practice modules in the implementation of digital and communication systems that have multi-input and multi-output devices. Partner problems are industry technology 4.0 and teacher competence. Industry 4.0 technology issues are implemented in practical training modules that are useful as learning media that can be implemented for various applications. The problem of teacher competence with training and development of learning media so as to be able to create and innovate in digital and communication systems. The method used in this activity is a discussion of technology issues, so that an explanation of the solution to be offered will be obtained, by demonstrating the teaching aids with practice trials and finally, observing activities to see the results of the activities. The results of this activity increase the competence and knowledge of vocational schools by marked the participants are able to operate and implement modules.

Keywords: Arduino, Digital, Communication, Industry 4.0

\section{Pendahuluan}

Fungsi dan peran sekolah sangat penting untuk menghasilkan lulusan yang siap berkompetisi di pasar kerja dalam level middle skill pada Sekolah Menengah Kejuruan (SMK) yang merupakan wadah untuk menuntut ilmu berupa pengetahuan, keterampilan dan kepribadian. Berlatar belakang dari tujuan pendidikan seperti yang diamanahkan undang-undang yaitu Undang-Undang No. 20 Tahun 2003 tentang Sistem Pendidikan Nasional. Dalam undang-undang dinyatakan bahwa penyelenggaraan pendidikan wajib memegang beberapa prinsip, yakni pendidikan diselenggarakan secara demokratis dan berkeadilan serta tidak diskriminatif dengan menjunjung tinggi hak asasi manusia, nilai keagamaan, nilai kultural, dan kemajemukan bangsa dengan satu kesatuan yang sistemik dengan sistem terbuka dan multimakna.
Sekolah Menengah Kejuruan berisi kumpulan mata pelajaran yang masing-masing mata pelajaran tersebut memiliki tujuan pembelajaran untuk mencapai kompetensi keahlian yang dipersyaratkan. Salah satu mata pelajaran pada kurikulum jurusan teknik elektronika dan komputer. Sistem operasi atau operating system adalah sebuah program yang ditujukan untuk melakukan pengaturan terhadap sumber daya yang ada dan program aplikasi lain yang dibuat. Namun biasanya sistem operasi dibuat untuk komputer dengan spesifikasi yang tinggi (PC, Mainframe). Saat ini banyak perangkat elektronik yang dibuat dengan menggunakan Mikrokontroler. Mikrokontroler merupakan salah satu dari alat pengendali yang digunakan untuk pengendalian otomatis. Mikrokontroler memiliki aplikasi yang luas, untuk berbagai keperluan, seperti implementasi menggunakan mikrokontroler (Hidayati, dkk, 2017) 
dan gabungan antara PLC-Mikro dengan Leader Diagram (Artanto, 2012) . Modul mikrokontroler yang dirancang untuk sarana praktik siswa-siswi adalah mikrokontroler tipe yang berbasis arduino. Arduino merupakan mikrokontroller dengan port input dan output yang diprogram oleh bahasa pemrograman C (Rachman, 2018). Pemilihan mikrokontroler arduino ini adalah mudah digunakan untuk berbagai aplikasi, sangat membantu bagi guru dan siswa-siswi yang baru mengenal dan belajar tentang mikrokontroller. Fungsi library (code program siap dipakai), sehingga untuk mengakses hardware sangat banyak. hardware tersebut seperti bluetooth, berbagai macam sensor, GSM board, GPS dan lainnya. Implementasi dari dari mikrokontroler seperi smart home (Rachman, 2017) untuk pemantauan kondisi rumah dimana saja, ada juga pemantauan gas metan pada pembuangan sampah TPA Manggar Balikpapan (Rachman, 2018) dan implementasi pada robot pemadam (Hidayati, 2018)

Jurusan yang ada di Sekolah Menengah Kejuruan banyak yang belum mengenal atau mengetahui tentang Arduino sehingga tim jurusan teknik elektro Politeknik Negeri Balikpapan melakukan pelatihan mengenai mikrokontroler arduino.

Berdasarkan analisis situasi di SMK Balikpapan masih mengalami berbagai permasalahan diantanya:

1. Permasalahan terkait mikrokontroller sebagai media praktik:

a. Mikrokontroller sebagai ilmu yang baru.

b. Ketidaktahuan atas arduino itu sendiri.

2. Permasalahan kompetensi guru:

a. Kompetensi guru dalam sistem kendali berbasis arduino.

b. Jumlah guru yang menguasai mikrokontroller masih terbatas.

Melihat permasalahan yang dihadapi mitra, maka perlu prioritas terhadap permasalahan, diantaranya adalah Penjelasan mengenai mikrokontroller itu sendiri, serta memberikan beberapa contoh yang mudah dipahami, dan peningkatan kompetensi Guruguru pengajar khususnya pada mata pelajaran.

\section{Bahan dan Metode}

Kegiatan ini dilaksanakan dengan menggunakan pendekatan metode diskusi, ceramah, demonstrasi, praktik langsung, dan observasi seperti pada gambar 1.

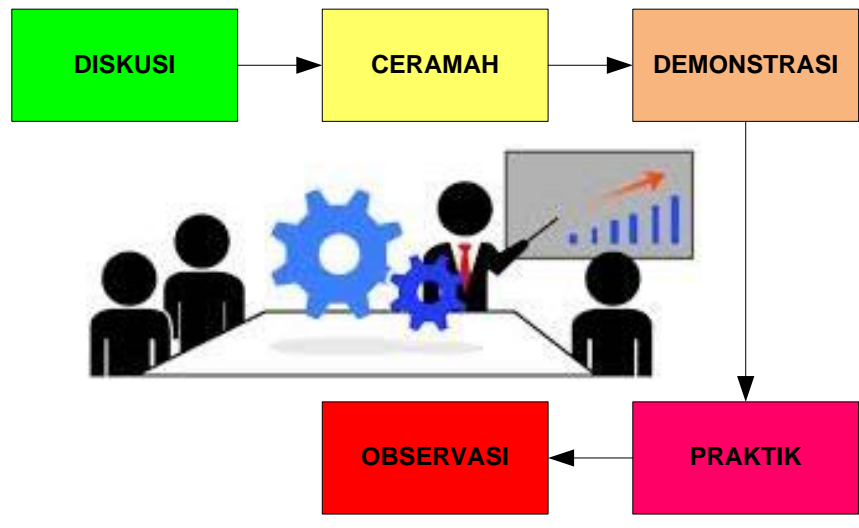

Gambar 1 Pendekatan Metode Kegiatan PkM

\section{Langkah 1: Metode diskusi}

Diskusi digunakan sebagai media komunikasi saat peninjauan kondisi lapangan akan ketersediaan modul praktik mikrokontroller dan materi pembelajaran tentang mikrokontroller. Selain itu, sebagai bahan pertimbangan akan mitra kegiatan yang akan diadakan untuk mendapatkan pelatihan.

\section{Langkah 2: Metode ceramah}

Ceramah digunakan dalam proses penyampaian materi pelatihan, selain itu digunakan juga dalam memberikan pengarahan kepada mitra untuk meningkatkan penggunaan modul mikrokontroller seperti pada gambar 2. Pada metode ceramah penyampaian materi mikrokontroler terbagi menjadi 2 bagian, pertama dasar dalam memahami mikrokontroler seperti arsitektur dan fungsi dari input dan output. Kedua yaitu pemahaman akan struktur pemrograman dasar dalam membangun sistem tertanam.

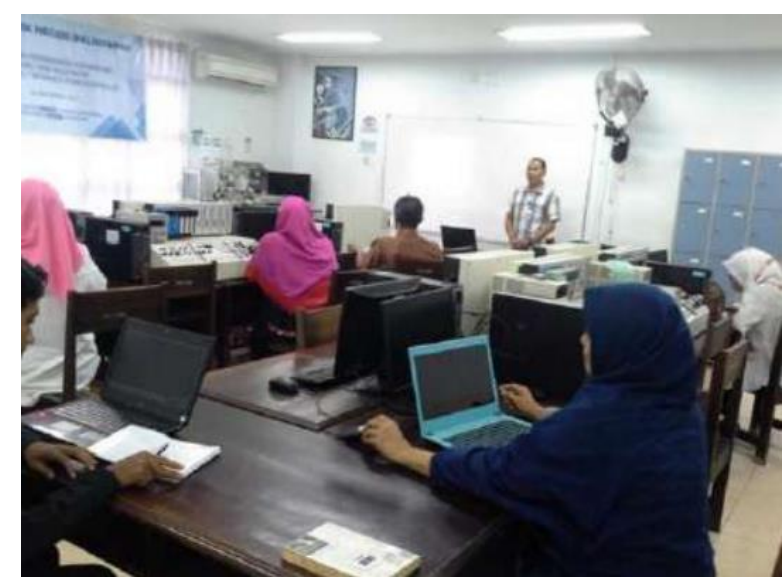

Gambar 2 Penyampaian Materi kepada Guru oleh Tim Dosen

Penyampaian kepada siswa SMK oleh Mahasiswa dilakukan dengan pengenalan akan fungsi mikrokontroler dalam kehidupan sehari-hari dan tip dan trik sederhana dalam mempelajarinya, kegiatan tersebut seperti pada gambar 3 . 


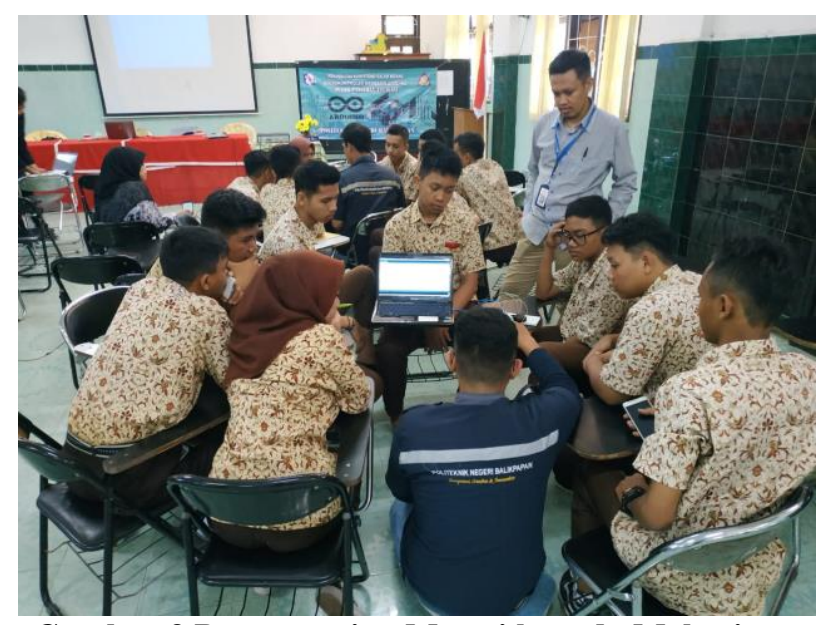

Gambar 3 Penyampaian Materi kepada Mahasiswa

\section{Langkah 3: Metode demonstrasi}

Demonstrasi digunakan dalam proses memberikan contoh dalam setiap pelatihan, sehingga memberikan kemudahan kepada mitra dalam memahami materi yang disampaikan. Kegiatan ini diawali dengan praktik dan contoh sederhana seperti cara pemrograman mikrokontoler ke media. Hasil demonstrasi akan menggambarkan implementasi dari aplikasi nyata yang terdapat pada kehidupan seharihari, seperti lampu lalu lintas, indikator kondisi udara, dan lainnya. Demonstrasi dilakukan seperti pada gambar 4.

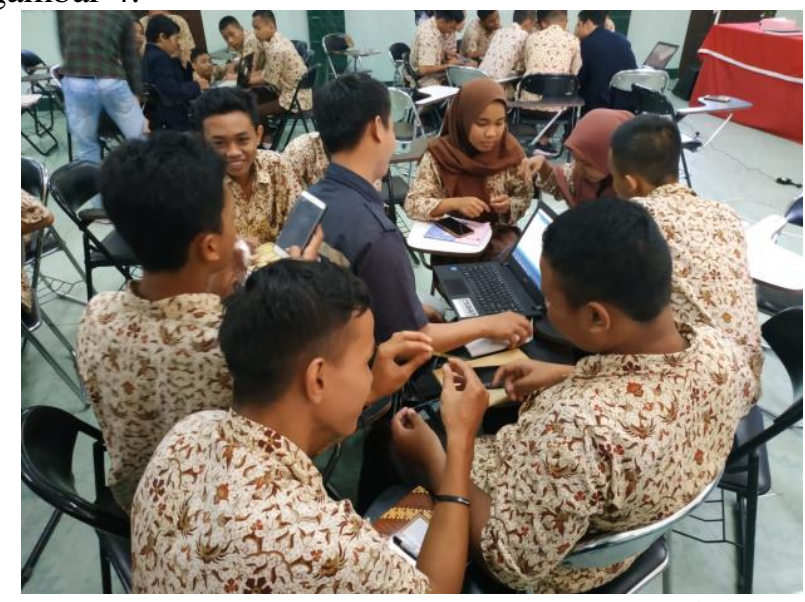

Gambar 4 Demonstrasi dan Praktik Pada Siswa

\section{Langah 4: Metode praktik}

Praktik digunakan untuk mengaplikasikan modul mikrokontroler arduino seperti pada gambar 5. Dimana modul-modul ini merupakan media pembelajaran dalam beberapa mata kuliah dalam sistem digital dan komunikasi yang dapat diterapkan pada sekolahsekolah dan kampus.

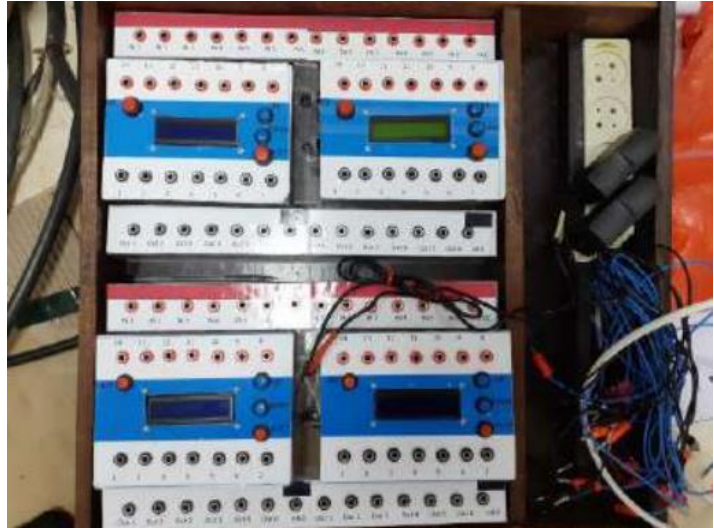

Gambar 5 Implementasi Pada Sistem Digital

Pada gambar 5, mikrokontroler diimplementasikan pada gerbang-gerbang logika dasar berbasis 14 pin. Modul ini diharapkan dapat menggantikan komponen-komponen dasar sistem digital seperti integrated circuit (IC) seperti gerbang or, nor, and, nand dan lainnya. Manfaat dari modul ini akan mengurangi penggunaan IC yang berbagai macam jenis sehingga hanya cukup menggunakan 1 modul untuk mewakili dari berbagai IC. Selain itu modul ini juga dapat saling terintegrasi membentuk rangkaian sesuai dengan tujuan penggunaan dalam menggabungkan berbagai macam gerbang logika.

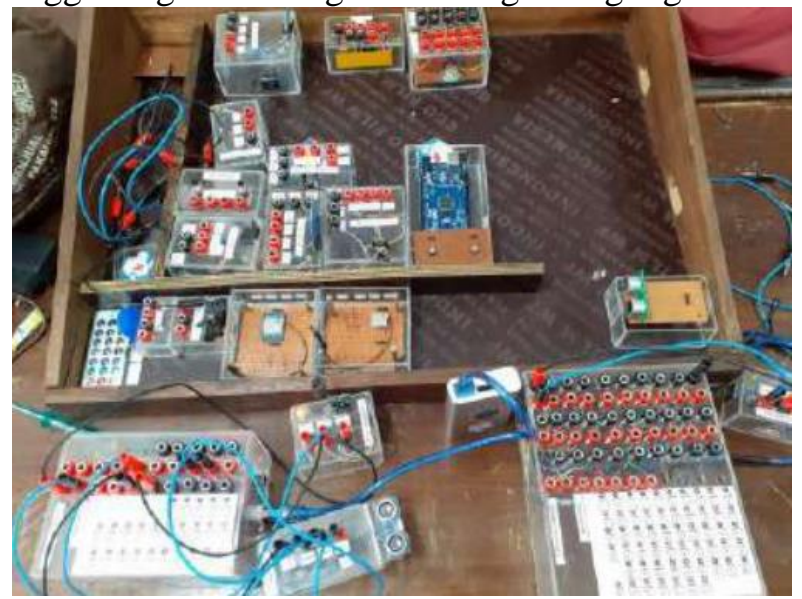

Gambar 6 Implementasi Pada Sistem Komunikasi

Pada gambar 6, Implementasi mikrokontroler yang diintegrasikan dengan sistem komunikasi. Tujuan dari modul ini adalah untuk memahami akan fungsi dan peran komunikasi dalam sistem kendali untuk menunjang era industry 4.0. Setelah memahami akan fungsi dari modul yang dikenalkan maka para peserta pelatihan melakukan uji coba modul seperti pada gambar 7 . 


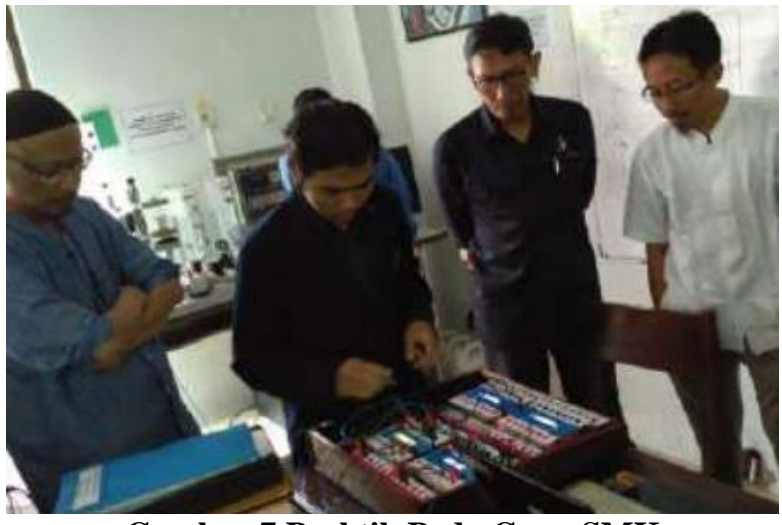

Gambar 7 Praktik Pada Guru SMK

Tujuan dari praktik diharapkan mampu mengembangkan dan menerpakan modul yang telah dipelajari ke Sekolah vokasi pada masing-masing instansi. Mulai dari tahapan dasar hingga pengembangan dan implentasi mikrokontroler dalam kehidupan sehari-hari dan industri.

\section{Langah 5: Metode Observasi}

Observasi digunakan untuk mengawasi dan mencatat kegiatan PkM dengan sengaja, sistematis dan selektif guna mendapatkan hasil dan kesimpulan dari kegiatan. Selain itu juga memiliki target capaian atau luaran dari kegiatan yang dilakukan seperti pubilkasi pada media masa dan jurnal atau seminar.

\section{Hasil dan Pembahasan}

Pada kegiatan Pengabdian Kepada Masyarakat (PKM) ini dirancang modul sistem pengendalian dengan multi input - multi output yang dapat digunakan sebagai alat praktik di SMK Balikpapan. Modul ini dirancang beserta program aplikasi dengan menggunakan bahasa $\mathrm{C}$ sebagai bahasa pemrograman pada pengendali utama mikrokontroller Arduino. Selain itu, dalam meningkatkan kompetensi Guru dilakukan pelatihan secara intensif dengan menggunakaan modul praktik Arduino yang dirancang untuk mempermudah dalam memahami dalam implementasi dalam mata pelajaran di sekolah vokasi.

Untuk menyelesaikan permasalahan akan kompetensi guru SMK, tim melakukan pelatihan penggunaan modul praktik arduino. Sosialisasi modul praktik dan disampaikan kepada siswa dan Guru SMK oleh Tim Poltekba agar dapat dimanfaatkan maksimal.

Demonstrasi dan praktik dilakukan kepada Siswa dan Guru SMK agar dapat menggunakan modul praktik pada saat pelaksanaan pratikum. Dalam kegiatan ini, siswa diinformasikan akan tersedianya modul praktik yang akan mereka gunakan setelah pelaksanaan PkM. Sehingga mahasiswa dapat memaksimalkan modul tersebut secara bersama.

Hasil dari proses kegiatan Pengabdian kepada Masyarakat (PkM) yang dilakukan menghasilkan suatu kesan positif bagi para guru dan siswa di SMK Balikpapan. Sebagai contoh para siswa dan guru yang hadir dalam pelatihan sangat antusias dalam menyimak materi dan demonstrasi yang kami selaku tim PkM penyelengara. Beberapa siswa yang sebelumnya sudah pernah mengikuti lomba kreatifitas teknologi sangat aktif dalam menanyakan system kerja dan permasalahan yang sering terjadi pada Arduino. Sehingga mereka yang belum mengenal Arduino dapat mengerti dan dapat mengaplikasikan di kemudian hari.

\section{Kesimpulan dan Saran}

Berdasarkan kesimpulan dapat diberikan saran yang berkenaan dengan pengembangan dan penyempurnaan modul untuk pengabdian masyarakat selanjutnya:

1.Diharapkan modul yang telah dirancang dapat direalisasikan dengan membuat prototype simulasi kontrol sehingga dapat mempermudah proses pembelajaran dan dapat menambah pengetahuan mengenai sistem kontrol.

2. Sebaiknya untuk dapat di kembangkan lagi modul I/O yang digunakan agar dapat lebih banyak pengetahuan dalam pemrograman dan dapat dijalankan melalui modul I/O.

3.Dalam pembuatan modul I/O alamat untuk pin masing masing input dan output harus diberikan agar memudahkan dalam proses pengkabelan (wiring).

4.Peletakan komponen dalam modul I/O membutuhkan kerapian dan kesesuaian dalam penempatan input dan output agar lebih memudahkan dalam proses pengkabelan.

Adapun dari segi Peningkatan Kompetensi pada sekolah SMK adalah:

1.Diharapkan dapat Lebih dikembangkan ke teknologi industri 4.0

2.Durasi pelatihan dapat lebih lama agar materi dan praktik dapat diterima dengan baik

3.Perlunya pengembangan mata pelajaran untuk menjawab tantangan teknologi industri 4.0.

\section{Ucapan Terima Kasih}

Saya ucapkan terima kasih kepada P3M Politeknik Negeri Balikpapan atas bantuan yang diberikan dalam terlaksananya kegitan PkM ini, serta mitra SMK Balikpapan dalam meluangka waktu untuk mengikuti kegiatan yang diselenggarakan.

\section{Daftar Rujukan}

Artanto, D. (2012). 60 Aplikasi PLC-Mikro.”, PT. Elex Media Komputindo.

Hidayati, Q., Rachman, F.Z., Yanti, N., Jamal, N., Suhaedi (2017). Desain Model dan Simulasi PLC-Mikrokontroler sebagai Modul Pembelajaran Berbasis PLC. JTERA - Jurnal Teknologi Rekayasa, 2(2), 73-82 
Hidayati, Q., Rachman, F.Z., Yanti, N. (2018). Intelligent Control System of FireExtinguishing and Obstacle-Avoiding Hexapod robot. KINETIK, 3(1), 1-10

Rachman, F.Z. (2018). Mikroprosesor dan Teknik Antar Muka. Buku Ajar Politeknik Negeri Balikpapan.

Rachman, F.Z. (2017). Smart Home Berbasis IoT. Seminar Nasional Inovasi Terknologi Terapan, (pp. 369-374). Balikpapan.

Rachman, F.Z. (2018). Sistem Pemantau Gas di Tepat Pembuangan Sampah Akhir Berbasis Internet og Things. Jurnal Teknologi dan Sistem Komputer, 6(3), 100-105.

Undang-Undang No.20 Tahun 2003 Tentang Sistem Pendidikan Nasional 